\title{
"Três apitos": lirismo e violência em Noel Rosa
}

\author{
[ "Três apitos": lyricism and violence in Noel Rosa
}

\section{Guto Leite $^{\mathrm{I}}$}

RESUMO - Este artigo procura demonstrar como subjaz em uma das mais conhecidas canções de amor de Noel Rosa um forte recorte de classe que opõe um confortável jovem representante da pequena burguesia carioca a uma operária trabalhadora da fábrica de tecidos. No decorrer da canção, a ambiguidade dos elogios é crescente e faz despontar nos versos doses sensíveis de violência e arbítrio, lembrando outro narrador célebre, Bento Santiago, que mascara reificação e propriedade do outro em expressões de amor. Ao cabo, considerando também a entoação, é possível até mesmo duvidar de que a canção se dirija à operária, como parece, levando-nos a crer que seja uma mensagem entre pares sobre uma malfadada conquista amorosa. - PALAVRAS-CHAVE • Canção popular; lirismo; violência; luta de classes. • ABSTRACT - This article aims to demonstrate how there is a clear class struggle hidden in one of the most notorious and extraordinary Noel Rosa's love songs that opposes a comfortable and young representative of the carioca burgeoisie and a cloth factory workwoman. In the song, the ambiguity of the compliments is crescent, bringing out violence and arbitrariness, evoking another famed narrator, Bento Santiago, who masks reification and slavery in expressions of love feeling. In the end, by confering intonation, it's even possible to doubt if the song really is adressed to the workwoman as it seems, leading us to believe that is a inner message between equals about a unsuccessful love conquest. • KEYWORDS · Song; lyricism; violence; class struggle.

Recebido em 20 de março de 2017

Aprovado em Io de abril de 2017

LEITE, Guto. “Três apitos”: lirismo e violência em Noel Rosa. Revista do Instituto de Estudos Brasileiros, Brasil, n. 66, p. I60-I7I, abr. 20I7.

DOI: http://dx.doi.org/Io.II606/issn.23I6-90IX.voi66pI6o-I7I

I Universidade Federal do Rio Grande do Sul (UFRGS, Porto Alegre, RS, Brasil). 
Ouvi pela primeira vez "Três apitos", o samba lento de Noel Rosa, como uma canção de amor, o que de fato ela é. Composta provavelmente no final de I93I, burilada ao longo de I932 e editada, finalmente, em I933, só ganhou sua primeira gravação em disco vinte anos mais tarde, em I95I, por Aracy de Almeida, com arranjos de Radamés Gnatalli, restando inédita, portanto, por duas décadas ${ }^{2}$. Foi exatamente essa a gravação que ouvi primeiro. Feita para um projeto ambicioso da gravadora Continental à época de seu lançamento, um álbum com três discos de $78 \mathrm{rpm}$, seis canções, do Poeta da Vila, que logo resultaria em um segundo álbum, dois meses depois, com mais três discos e seis canções, em função do sucesso alcançado. Essa iniciativa estava na esteira da recuperação da música popular brasileira ocorrida na década de I950 e que colocaria de vez o compositor no radar de cancionistas como Chico Buarque e Caetano Veloso, crianças ainda àquela altura.

Recupero o contexto dessa primeira gravação de "Três apitos" por diversos motivos. O primeiro deles para frisar que Noel Rosa não gravou nem deixou gravar essa canção em vida. Aracy de Almeida disse que o compositor não gostava do samba, o que é importante, como vamos ver, mas lateral por ora. O segundo motivo, para indicar o quanto essa primeira gravação póstuma ("a voz do morto"3?) conformou a canção a certa leitura romântica, reforçada pela maneira de cantar pungente de Aracy e pelo arranjo centrado nas cordas de Radamés - interpretação tão forte, que influenciaria incontáveis gravações posteriores, como, por exemplo, a de Tom Jobim (I99I), Ney Matogrosso (I990), Maria Bethânia (2006), Rosa Passos (20II) e mesmo Chico Buarque (2002) 4 , cancionista de ironia e malícia análogas às de Noel. Vale

2 Para os dados acerca de Noel Rosa e do contexto da canção, me vali de: MÁXIMO, João; DIDIER, Carlos. Noel Rosa: uma biografia. Brasília: Editora da Universidade de Brasília/Linha Gráfica Editora, I990, sobremodo p. I84 e ss.

3 Sobre as consequências da associação de Aracy de Almeida a Noel Rosa e os significados da canção de Caetano, “A voz do morto”, ver: SANTOS, Daniela Vieira dos. A formalização da derrota: sobre "Eles” e "A voz do morto”, de Caetano Veloso". Revista do Instituto de Estudos Brasileiros, n. 6I, agosto de 2015.

4 Meus agradecimentos ao site sempre providencial de Maria Luiza Kfouri: DISCOS DO BRASIL. Uma discografia brasileira - por Maria Luiza Kfouri. Disponível em: < http://www.discosdobrasil.com.br/>. Acesso em: 20 mar. 2017. 
dizer que seguir a vereda romântica não significa necessariamente desconhecer ou amainar a leitura menos adocicada que irei propor neste ensaio. Pode ser até que a manutenção da roupagem de "declaração amorosa" amplifique os traços de violência que pretendo identificar. Por fim, é importante notar que há aqui, sobrepostos, ao menos dois tempos distintos quanto à maneira como ouvimos canção popular, isto é, há pelos menos dois horizontes diferentes de recepção. O primeiro deles, a época de ouro dos anos de I930 a I945 - sem nos esquecermos de que chamar "de ouro" tal ou qual período tem sempre ares de idealização regressiva -, de quando tendemos a ouvir as canções sem pressupor que elas possam estar dizendo algo muito distante do que dizem ou seu contrário; e um segundo tempo, depois da bossa nova, de Chico Buarque e do tropicalismo, em que precisamos suspeitar sempre do que se apresenta na superfície da canção, seja porque a agudeza dos compositores é capaz de camuflar ironias mordazes ou reflexões muito sofisticadas, como em "Pelas tabelas" ou "Coisas do mundo, minha nêga"7, seja porque os dados do contexto são capazes de inverter aquilo que está sendo entoado, como em "Baby". Ainda improvisadamente, em aula, costumo dizer que se trata do aporte dos cancionistas hiperletrados à canção popular, em comparação ao aporte de cancionistas letrados, na geração anterior.

Nesse sentido, minha suspeição sobre "Três apitos" depende de um modo de escutar canções tornado ordinário pela geração seguinte à de Noel, o que não quer dizer que não possa já ser identificado em algumas canções de alguns compositores nos anos I930, ou mesmo que tensões pouco conscientes aos cancionistas acabem por imprimir na forma cancional sentidos imprevistos pelos autores - Noel teria afirmado, por exemplo, que “'Três apitos' resume o romance mais sincero de minha vida gloriosamente romântica...”', referindo-se a Fina, uma operária com quem o autor teria tido um namorico. Como se verá, desenvolverei uma leitura bastante avessa ao que Noel manifestou sobre sua própria canção.

Feito o preâmbulo, começo a analisar a canção e a demonstrar a maneira gradativa com que algumas tensões se apresentam ao longo das estrofes. É imperativo que se ouça uma das dezenas de versões da canção antes ou durante a leitura da letra abaixo, posto que minha análise conjugará elementos da letra e da entoação.

\title{
Três apitos
}

\author{
Quando o apito \\ Da fábrica de tecidos \\ Vem ferir os meus ouvidos
}

5 SEVERIANO, Jairo. Uma história da música popular: das origens à modernidade. São Paulo: Editora 34, 2008.

6 BUARQUE, Chico. Pelas tabelas. In: . Chico Buarque. Produção: Homero Ferreira. Polygram, I984.

7 VIOLA, Paulinho da. Coisa do mundo, minha nêga. In: . Paulinho da Viola. Produtor: Milton Miranda. Polygram, I968.

8 VELOSO, Caetano. Baby. In: VELOSO, Caetano; GIL, Gilberto et al. Tropicalia ou panis et circensis. Phillips, I968.

9 MÁXIMO, João; DIDIER, Carlos, op. cit., p. I85. 
Eu me lembro de você

Mas você anda

Sem dúvida bem zangada

E está interessada

Em fingir que não me vê

Você que atende ao apito

De uma chaminé de barro

Por que não atende ao grito tão aflito

Da buzina do meu carro

Você no inverno

Sem meias vai pro trabalho

Não faz fé com agasalho

Nem no frio você crê

Mas você é mesmo

Artigo que não se imita

Quando a fábrica apita

Faz reclame de você

Nos meus olhos você lê

Que eu sofro cruelmente

Com ciúmes do gerente impertinente

Que dá ordens a você

Sou do sereno

Poeta muito soturno

Vou virar guarda-noturno

E você sabe por quê

Mas você não sabe

Que enquanto você faz pano

Faço junto do piano

Estes versos pra você.

(Noel Rosa)

A canção principia por uma narração - embora algumas estrofes posteriores sejam melhor caracterizadas como interpelação ou loa. Indica, em sua abertura, um fato que ocorre reiteradamente, o soar do apito da fábrica de tecidos, e a lembrança de uma mulher despertada no eu cancional e a quem a canção se dirige diretamente ("você"). O que pode parecer simples já insinua algumas linhas que constroem outro sentido para a canção, que devemos acompanhar. Num primeiro nível, o dado de que a fábrica referida é possivelmente a fábrica de tecidos Confiança, fundada no 
final do século XIX, I885, e localizada próximo à casa de Noel. Dado banal se não observarmos o título da canção: três apitos se referem aos três apitos da fábrica pela manhã - às 5h45, para acordar os operários que moravam nas redondezas, às $7 \mathrm{~h}$, o horário de entrada dos trabalhadores, e às 7 h45, depois do qual se perdia o dia de trabalho ${ }^{\mathrm{To}}$.

Além da oposição entre a vida boêmia de músicos e compositores e a vida de operário, evidenciada na estridência do apito tão cedo pela manhã ${ }^{\text {II }}$ - e concretizada na escolha do verbo "ferir" -, os três apitos funcionam como um ultimato, um aviso derradeiro depois do qual não há mais o que fazer. Digo de uma vez, tornando estranhamente próximas as figuras do eu da canção e aquele que pode fazer soar o apito da fábrica, dando um ultimato à operária. O numeral três aqui, peculiarmente, não indica uma quantidade de objetos no espaço, mas no tempo. Concomitantemente, o que também já anuncia o que se seguirá, a memória despertada parece mais involuntária do que voluntária, como se ele não pudesse evitar lembrar-se da operária; assim, os apitos estariam mais para o pio da coruja de Paulo Honório, que lembra Madalena ${ }^{\mathrm{I} 2}$, do que para as madeleines de Proust No caminho de Swann ${ }^{\mathrm{I3}}$. Dizendo de outro modo, o apito da fábrica é o gatilho que suscita uma lembrança incômoda ao eu cancional, incômodo que pode ser deduzido da impossibilidade de relacionamento, numa leitura mais direta, ou mesmo alguma culpa de classe, como buscarei desenvolver. O portal está feito.

A segunda estrofe, ainda pensando pela narrativa, insere explicitamente a primeira contradição ("Mas") indicando que a pessoa a quem se conta está bem zangada por algum motivo, que não será explicado na canção, mas que podemos desconfiar, mais adiante, serem as manifestações de ciúmes do eu cancional. Interessam sobremodo nessa segunda estrofe as características pelas quais se constrói para nós a musa da canção. De maneira pouco comum para as descrições amorosas, orbitam a representação da operária, as ideias de zanga, interesse, fingimento e, duas estrofes depois, teimosia - , o que será comentado em tempo, por ser uma espécie de despiste do narrador. Inevitável pensar que aqui nasce o primeiro ressabio sobre o aspecto conativo da canção, isto é, de ela estar realmente sendo dirigida à operária. Ou a voz que canta acha haver algum charme na representação de uma mulher geniosa para a mulher para quem ele canta, ou podemos começar a suspeitar, mesmo que timidamente, que a canção é falsamente conativa, do ponto de vista de gênero, isto é, Noel estaria cantando para outros homens, mas também do ponto de vista de classe, isto é, Noel não estaria cantando para operários.

Io Idem, ibidem.

II Para outra canção em que a vida noturna aparece em tensão com o raiar do dia, ouvir "Olê, olá", de Chico Buarque, e conferir a análise de: TATIT, Luiz; LOPES, Ivã. Olê, olá: sol contra samba. In: Elos de melodia e letra. São Paulo: Ateliê Editorial, 2008, p. 79-97.

I2 RAMOS, Graciliano. São Bernardo. 45. ed. Rio de Janeiro: Record, I985.

I3 PROUST, Marcel. Em busca do tempo perdido. Volume I: No caminho de Swann. I9 ed. Tradução de Mário Quintana. Porto Alegre: Globo, I998. 
A canção, que vinha em chave estritamente passional ${ }^{14}$, apresenta na terceira estrofe uma nova melodia e marca com precisão os acentos do samba, desenhando uma curva descendente entre a nota mais alta e a nota mais baixa da melodia ${ }^{\mathrm{IS}}$. Uma primeira pista sobre os silêncios que se colocavam até então é dada, e em forma de pergunta, aqui parafraseada: "Por que você atende aos apitos de uma chaminé de barro e não atende aos gritos tão aflitos da buzina do meu carro?”' ${ }^{\text {. }}$. Desdobrada desse modo, é possível perceber sem grandes dificuldades a violência de sua formulação. Quem faz a pergunta decerto se pensa socialmente acima da operária e também daquele que faz soar o apito, de quem sente ciúmes. É possível identificar ainda, sem qualquer extrapolação na leitura, que os ciúmes são da obediência da operária e não obrigatoriamente de sua atenção ou afeto. Reordenada a pergunta, poderia ser algo como: por que você o obedece tão prontamente e não me obedece da mesma forma? $\mathrm{O}$ apito é uma extensão do poder desse outro homem, que veremos ser o gerente, sobre a operária, tal como o carro é uma extensão do poder do eu cancional sobre ela, com a particularidade de só o carro aparecer personificado ("grito tão aflito"), como se dono do carro e carro se fundissem. Entoativamente se desfaz a chave passional, associada a um falar doce, ou a um cantar consigo, imaginativo, reflexivo, e entra um princípio de exasperação, em chave figurativo-temática, que aponta para o eu cancional e o desvela. É nessa exasperação que ele mostra suas garras, antes de se velar novamente nos elogios e no retorno à melodia nacional a partir da estrofe subsequente. (Forçando um pouco a barra: defendo que a distância entre a nota mais alta e a nota mais baixa da entoação de uma parte dessa terceira estrofe seja a representação entoativa da distância social entre os amantes.)

Reunindo um pouco dos elementos abordados até aqui: não se trata, como acreditam Máximo e Didier, de expressão de enternecimento ${ }^{\text {I7 }}$. Tampouco, embora Tatit vá fornecer a chave mais valiosa para a leitura que estou propondo, discordo do semioticista, que diz que a disjunção amorosa expressa na canção é contingência

I4 TATIT, Luiz. O cancionista. 2. ed. São Paulo: Edusp, 2002, p. 22-24.

I5 Ibidem, p. 54 .

I6 Eis uma preciosa observação de Tom Jobim, segundo relato de Ruy Castro: "No primeiro caso, a falta de meias e de agasalho pode significar teimosia diante do frio, mas pode também significar sarcasmo em relação à pobreza da moça e à sua impossibilidade de comprar essas peças". Tom dedilhou a frase musical de "Três apitos”, que contém os versos, "Você que atende ao apito/ De uma chaminé de barro/ Por que não atende ao grito/ Tão aflito/ Da buzina do meu carro?”, e se deixou ficar nessas últimas palavras, repetindo as notas ao piano. “'Ora, vejam só', exclamou, como se acabasse de fazer uma descoberta. 'É aquela sequencinha melódica das buzinas de antigamente! O Noel era danado. [...] Essa moça que vai sem meias pro trabalho é uma moça pobre, não pode comprar um agasalho. Mas tem aquela beleza, aquele fogo das moças simples, o que levou Noel a dizer que ela merecia um réclame. [...] Na maioria das letras daquele tempo, antes da Bossa Nova, a mulher era sempre uma bandida, uma traidora. Mas, com Noel, isso não acontecia, porque ele gostava das mulheres." CASTRO, Ruy. O umbigo musical do Brasil. In: CASTRO, Ruy. A onda que se ergueu no mar - novos mergulhos na bossa nova. São Paulo: Companhia das Letras, 200I, p. 55. Agradeço ao parecerista designado pela Revista do Instituto de Estudos Brasileiros pela indicação dessa passagem, que eu desconhecia. I7 MÁXIMO, João; DIDIER, Carlos, op. cit., p. I84. 
lamentável e não fatalidade irremediável ${ }^{18}$. É preciso se afastar desse narrador para perceber que o lamento é estratégia narrativa para o exercício de certa violência por meio da canção. Para introduzir uma analogia que desenvolverei adiante, vejamos a abertura do segundo capítulo de Dom Casmurro, de Machado de Assis:

Agora que expliquei o título, passo a escrever o livro. Antes disso, porém, digamos os motivos que me põem a pena na mão.

Vivo só, com um criado. A casa em que moro é própria; fi-la construir de propósito, levado de um desejo tão particular que me vexa imprimi-lo, mas vá lá. Um dia, há bastantes anos, lembrou-me reproduzir no Engenho Novo a casa em que me criei na antiga Rua de Mata-cavalos, dando-lhe o mesmo aspecto e economia daquela outra, que desapareceu ${ }^{\text {I9. }}$.

Similarmente, a construção do ethos de "cavalheiro distinto e sentimental"º, casmurro, com contas a pagar sobre o passado, almeja um alvará para que possa cometer uma grande violência por meio do romance que escreve, qual seja, atribuir à sua falecida esposa, Capitu, a culpa irreversível da suposta condição melancólica em que vive o narrador. Voltando à canção, também indiquei, pela entoação, o momento em que o eu cancional se enraivece e o motivo, ciúmes, assim como realcei as figuras do gerente e da operária. Diga-se de passagem que, salvo a representação do processo social de então, das dificuldades econômicas agudas a partir da crise de I929, que promoveu um contato maior entre classes sociais distintas, da formação do operariado fabril no Rio de Janeiro, da ascensão da canção popular, não como gênero rentável, mas como prestigioso, não vejo como confundir a voz do eu cancional com a voz de Noel Rosa.

A quarta e a quinta estrofes, de volta à melodia inicial, são geralmente tomadas como exemplo de alto lirismo, de devoção à mulher amada. Na quarta estrofe, a expressão da teimosia da musa, que nem no frio acredita, indo à fábrica sem meias e desagasalhada. Na quinta, a afirmação de que a musa é única, "artigo que não se imita", e que o apito da fábrica é uma propaganda ("reclame") dessa unicidade. Nesse ponto, em que o eu cancional já se mostrou menos cortês ao perguntar o porquê da "preferência" da operária na estrofe anterior, fica difícil não entender os elogios em chave bastante ambígua. No primeiro caso, a falta de meias e de agasalho pode significar teimosia diante do frio, mas pode também significar sarcasmo em relação à pobreza da moça e à sua impossibilidade de comprar essas peças. No segundo caso, a estrofe pode indicar o quanto aquela operária é única para o eu cancional, mas também a aproxima, de maneira um tanto brusca, da esfera dos objetos e dos produtos, um artigo único cuja propaganda é feita pelos apitos da fábrica. Nesse ponto,

I8 TATIT, Luiz, op. cit., p. 54 .

I9 MACHADO DE ASSIS, Joaquim Maria. Dom Casmurro. Domínio público, p. I. Disponível em: <http://www. dominiopublico.gov.br/pesquisa/DetalheObraForm.do?select_action=\&co_obra=I888 $>$. Acesso em: 28 mar. 2017.

20 SCHWARZ, Roberto. A poesia envenenada de Dom Casmurro. Novos Estudos Cebrap, n. 29, março de I99I, p. 86. 
me parece, as condições de "patrão" e "empregada" estão postas. Além disso, voltamos a nos perguntar se os elogios estão sendo feitos para a musa ou sobre a musa. Isto é, pensando em códigos de referência compartilhados, para quem o comentário sobre as roupas e o elogio da teimosia funcionariam? E sobre a comparação da operária com um produto, quem ouviria essa comparação como uma eficiente cantada?

"Nos meus olhos você lê" principia uma das mais especiosas estrofes do cancioneiro brasileiro. Segundo Máximo e Didier ${ }^{2 I}$, teria sido composta posteriormente às outras estrofes, em I932, provocada por um relato, feito por Fina, musa de Noel, de assédio de um contramestre - nesse sentido, a vingança seria, em parte, uma tentativa de sublimação pela canção do ciúme real do artista. Biografias à parte, a estrofe escancara um mecanismo que Luiz Tatit desvelou em parte, mas recuou - a ser comentado logo adiante -, e que considero a chave crítica mais valiosa para a análise dessa canção. Quando antes o cancionista alinha a musa da canção, o apito da fábrica e a buzina do carro, já está indicando o triângulo de quereres que se forma entre a operária, o gerente, agora nominalmente indicado, e o proprietário, ou ao menos um simulacro de proprietário, porque imune à necessidade do trabalho, que chega de carro para paquerar a trabalhadora.

É possível, no entanto, seguir adiante e verificar que a força motriz da canção não é propriamente o ciúme, mas um despeito de patrão, ou patrãozinho, que reclama da maior proximidade, em relação a si, entre operária e gerente. Se há amor, o que quer que isso seja, há também ciúmes, despeito, posse, reação à autonomia feminina e arbítrio em nosso Dom Casmurro do Rio de Janeiro de I930. Com alguma dose de sadia irresponsabilidade e Casa grande e`senzala ${ }^{22}$, é possível dizer que a canção evoca o sinhozinho enciumado do capataz por seu trânsito e por sua lida junto à escrava dileta.

De maneira mais precisa e responsável, modula Roberto Schwarz, sobre o romance de Machado de Assis, analisando a continuidade subterrânea das relações escravocratas no Brasil:

A reciprocidade de vícios entre senhores e escravos, observada por Nabuco, se pode estender à relação entre senhores e clientela. Por outro lado, esta verdade local da sátira, interessante nela mesma, não lhe esgota o alcance. É como se nas circunstâncias brasileiras se apurasse e viesse à linha de frente uma dimensão do privilégio que nas sociedades europeias, onde o trabalho era livre, podia parecer inessencial, superada ou assunto de opereta, sem prejuízo da vigência profunda: o aspecto encasacado, melhorque-os-outros, antidemocrático, ou, em suma, o laço de origem entre a liberdade e a propriedade burguesa - que fala ao coração de José Dias - existe e até hoje não se esgotou por completo em parte alguma ${ }^{23}$.

São inúmeras as diferenças entre romance e canção, evidentemente: aquelas inerentes à distância entre as duas formas estéticas, a questão da culpa de Capitu e a

2I MÁXIMO, João; DIDIER, Carlos, op. cit., p. I84.

22 FREYRE, Gilberto. Casa-grande er senzala. 29. ed. Rio de Janeiro: Record, I994, capítulos IV e V.

23 SCHWARZ, Roberto, op. cit., p. 94 . 
ausência desse tema na canção, da parte da operária, uma estratificação maior das relações amorosas no romance, as diferenças relativas aos tempos em que as obras foram feitas etc. Duas das diferenças, contudo, merecem comentário, justamente porque iluminam as tensões presentes em "Três apitos" e nos ajudam a ler melhor todo o conjunto e, no caso deste ensaio, as duas estrofes que restam ser analisadas.

A primeira delas opõe o espaço dialógico ou polifônico do romance ao espaço monológico da canção ${ }^{24}$. Em outros termos, salvo a suspeição total do contrato de leitura, quando há travessão em Dom Casmurro, por exemplo, entendemos que é Capitu quem fala, por mais que o sentido do que fala possa ser deturpado depois, ou antes, pelo narrador. Na canção, pelo contrário, só ouvimos a voz do enciumado, enquanto a operária "fala" somente em gestos, todos eles descritos pelo eu cancional. Com isso medimos também a diferença de cálculo entre os autores e seus respectivos narradores. Se Machado constrói Bento Santiago como um mau detetive que altera a cena do crime, reorganizando as evidências e esperando a natureza detetivesca do leitor, Noel constrói a voz de um pequeno-burguês apaixonado pela operária, transformada, com efeito, em objeto de sua paixão, esperando que o leitor entenda o que ele sente e se mostre simpático à sua causa. Em suma, a isca de Machado é pela razão; a de Noel, pelos afetos.

Assim chegamos a uma segunda diferença especialmente significativa. Se a operação machadiana vela-desvela o mecanismo de autoridade de Bento Santiago, "como se para o leitor brasileiro as implicações abjetas de certas formas de autoridade fossem menos visíveis”" ${ }^{25}$ a estratégia de Noel, se é que é possível falar em estratégia, se faz por meio de um gesto de profunda integração, nos lançando para junto desse eu que sofre pelas recusas de sua amada, pelas impossibilidades de se aproximar. Se viramos o rosto para os resquícios de escravidão em Dom Casmurro, cantamos abraçados o insucesso amoroso do eu cancional de Noel - identificação que seria bastante improvável com Bento Santiago. Talvez por isso: se está em jogo "um moço rico, de família decadente, filho de mamãe, para o qual a energia e liberdade de opinião de uma mocinha mais moderna, além de filha de um vizinho pobre, provam ser intoleráveis" ${ }^{26}$, em "Três apitos", temos um moço de classe média, ascendente (apesar da crise), que se identifica com os valores, mesmo os mais nefastos, da elite, que se gaba de subir na vida e não vê limites, ao menos na canção, para a satisfação de seus desejos. Trazer para o privado, se der, para o íntimo, até mesmo a violência - numa versão aguda e perversa da cordialidade ${ }^{27}$.

Com o que foi acumulado até aqui, creio que seja possível enxergar melhor a crueldade espantosamente impecável com que Noel elabora as duas últimas estrofes. Antes disso, vale retornar a Tatit para inferir o público da canção, o "tu" a quem a canção é verdadeiramente entoada. O semioticista, após indicar a expressão comedida e o efeito de intimidade presentes em "Três apitos", afirma: "esta canção

24 BAKTHIN, Mikhail. Problemas da poética de Dostoievski. 3. ed. Tradução de Paulo Bezerra. Rio de Janeiro:

Forense Universitária, 2005.

25 SCHWARZ, Roberto, op. cit., p. 85.

26 GLEDSON, John apud SCHWARZ, Roberto, op. cit., p. 86.

27 HOLANDA, Sergio Buarque de. Raízes do Brasil. 26. ed. São Paulo: Companhia das Letras, 1995, p. I39 e ss. 
desperta a cumplicidade emotiva do ouvinte pela distribuição cuidadosa e moderada das tensões de frequência”28. Ou seja, está na entoação cancional e não somente na letra ou na melodia o gesto dessa voz que prima pelo afeto do ouvinte. A hipótese de Tatit não só reforça o que acabei de expor, mas desvenda a verdadeira interlocução que se estabelece em "Três apitos". Embora desde a primeira estrofe se ouça um cantar para a musa, como uma espécie de serenata em ausência, do "patrão" para a operária, a piscada de olho é lateral e busca junto ao ouvinte intimidade, mais do que isso, cumplicidade, num gozar juntos pela violência simbólica praticada contra as de baixo'29.

É sob essa luz que escolho ler as duas estrofes derradeiras, e toda a sua sinuosidade. "Sou do sereno/ Poeta muito soturno/ Vou virar guarda-noturno/ E você sabe por quê" não pode mais ser lida numa chave charmosa de tentativas a todo custo de se aproximar do ser amado. Deve ser lida, sim, como um chiste cuja origem só é possível para quem vê o trabalho como um tipo de cena, piada ou estratégia de conquista, para quem reduz o trabalho a um capricho, a um fetiche. $\mathrm{O}$ eu cancional não pensa nas dez ou doze horas de serão, nas condições adversas, no espaço apertado da guarita, mas na possibilidade de estar próximo à operária no começo e no fim da jornada de trabalho dela, perspectiva claramente distanciada acerca da natureza real e cotidiana dos ofícios, com a nota de que ainda mantém sobre a trabalhadora uma ascendência de autoridade. É impressionante como a voz dessa canção jamais se coloca, mesmo de brincadeira, numa condição de igualdade com a mulher "cortejada".

Operação análoga se dá nos versos seguintes, talvez os mais bonitos de toda a canção e que a encerram: "Mas você não sabe/ Que enquanto você faz pano/ Faço junto do piano/ Estes versos pra você". O acréscimo de uma vogal dentro da palavra "pano" ("piano"), além de exibir o virtuosismo do cancionista no manejo das palavras, dando concreção ao eu cancional e compondo junto ao piano a canção que ouvíamos até então - reforçando a presença da voz que canta no presente da entoação -, explicita a enorme distância social que há entre um e outra: ela passa os dias produzindo pano na fábrica de tecidos, e ele pode passar os dias no piano, compondo uma canção para ela. Na letra acrescentada pelo cancionista se expressa um intransponível abismo social. Com o perdão da redundância, volto a perguntar: trata-se de uma cantada ou de uma pilhéria? Ele pisca os olhos para ela ou para os seus, como se dissesse, "olha essa empregadinha!"? Artifício e luta de classes, entremeados.

Procurei neste ensaio perfazer uma leitura difícil e ingrata. Primeiro, por despertar o ouvinte para o quanto a violência suplanta o discurso amoroso em "Três apitos”, uma das mais conhecidas canções líricas de Noel Rosa. Segundo, por desnudar mecanismos que talvez o próprio cancionista rejeitasse em sua canção. Tentei ainda caminhar com a leitura de modo que a leitora ou o leitor se desfizessem da provável impressão original sobre a canção ao longo da travessia e passasse a descobrir “comigo” os signos da violência. Temo não ter conseguido mediar o necessário, mas

28 TATIT, Luiz. O cancionista, op. cit., p. 56.

29 Outro objeto estético que realiza uma construção análoga é o conto de Guimarães Rosa, "O famigerado", conforme leitura de: PACHECO, Ana Paula. Lugar do mito: narrativa e processo social nas Primeiras estórias de Guimarães Rosa. São Paulo: Nankin, 2006, p. 7I-80. 
estou certo de que ao menos alguma desconfiança pude cultivar na leitora ou no leitor deste texto. De minha parte, quero ouvir de novo outras canções de Noel e de outros grandes do período, Ary Barroso ou Dorival Caymmi, a conferir quantos sentidos, deliberados ou não, podem ser desencavados de suas canções.

\section{SOBRE O AUTOR}

GUTO LEITE é professor do Departamento de Letras Clássicas e Vernáculas do Instituto de Letras e coordenador da Especialização em Literatura Brasileira da Universidade Federal do Rio Grande do Sul (UFRGS).

E-mail: guto.leite82@gmail.com

\section{REFERÊNCIAS BIBLIOGRÁFICAS}

BAKTHIN, Mikhail. Problemas da poética de Dostoievski. 3. ed. Tradução de Paulo Bezerra. Rio de Janeiro: Forense Universitária, 2005.

CASTRO, Ruy. O umbigo musical do Brasil. In: . CASTRO, Ruy. A onda que se ergueu no mar. São Paulo: Companhia das Letras, 2001 .

DISCOS DO BRASIL. Uma discografia brasileira - por Maria Luiza Kfouri. Disponível em: <http://www. discosdobrasil.com.br $>$. Acesso em: 20 mar. 2017.

FREYRE, Gilberto. Casa-grande er senzala. 29. ed. Rio de Janeiro: Record, I994.

HOLANDA, Sergio Buarque de. Raízes do Brasil. 26. ed. São Paulo: Companhia das Letras, I995.

MACHADO DE ASSIS, Joaquim Maria. Dom Casmurro. Domínio público. Disponível em: <http://www. dominiopublico.gov.br/pesquisa/DetalheObraForm.do?select_action=\&co_obra=I888 $>$. Acesso em: em 28 mar. 20I7.

MÁXIMO, João; DIDIER, Carlos. Noel Rosa: uma biografia. Brasília: Editora da Universidade de Brasília/ Linha Gráfica Editora, I990.

PROUST, Marcel. Em busca do tempo perdido. Volume I: No caminho de Swann. I9. ed. Tradução de Mário Quintana. Porto Alegre: Globo, I998.

PACHECO, Ana Paula. Lugar do mito: narrativa e processo social nas Primeiras estórias de Guimarães Rosa. São Paulo: Nankin, 2006.

RAMOS, Graciliano. São Bernardo. 45. ed. Rio de Janeiro: Record, I985.

SANTOS, Daniela Vieira dos. A formalização da derrota: sobre "Eles" e "A voz do morto", de Caetano Veloso. Revista do Instituto de Estudos Brasileiros, n. 6I, agosto de 20I5. Disponível em: <http://www.scielo.br/ scielo.php?pid=So020-38742015000200056\&script=sci_abstract\&tlng=pt $\rangle$. Acesso em: 28 mar. 2017 . SCHWARZ, Roberto. A poesia envenenada de Dom Casmurro. Novos Estudos Cebrap, n. 29, março de I99I. SEVERIANO, Jairo. Uma história da música popular: das origens à modernidade. São Paulo: Editora 34, 2008. TATIT, Luiz; LOPES, Ivã. Olê, olá: Sol contra samba. In: . Elos de melodia e letra. São Paulo: Ateliê Editorial, 2008, p. 79-97. 
TATIT, Luiz. O cancionista. 2. ed. São Paulo: Edusp, 2002.

\section{REFERÊNCIAS DISCOGRÁFICAS}

BETHÂNIA, Maria. Maria Bethânia canta Noel Rosa e outras raridades (I965). Produtor: Ramalho Neto e Rodrigo Faour. Sony \& BMG, 2006.

BUARQUE, Chico. A música brasileira deste século por seus autores e intérpretes: Chico Buarque. Produtor: J.

C. Botezelli (Pelão). SESC São Paulo, 2002.

. Chico Buarque. Produção: Homero Ferreira. Polygram, I984.

JOBIM, Tom. Três apitos. In: ROSA, Noel. Songbook - Noel Rosa. Produtor: Almir Chediak. Lumiar Discos, I99I.

MATOGROSSO, Ney; RABELLO, Rafel. À flor da pele. Produtor: Mazzola. Polygram/Phillips, I99o.

PASSOS, Rosa. É luxo só. Produtores: Rosa Passos, Renata Borges e Luiz Felipe Caetano. Biscoito Fino, 20II. ROSA, Noel. Noel pela primeira vez, vol. 6. Produtor: Omar Abu Chahla Jubran. Velas/Funarte, 2000.

VELOSO, Caetano. Baby. In: VELOSO, Caetano; GIL, Gilberto et al. Tropicalia ou panis et circensis. Phillips, I968.

VIOLA, Paulinho da. Paulinho da Viola. Produtor: Milton Miranda. Polygram, I968. 